\title{
Article
}

\section{Characterization of Ag-exchanged clinoptilolite treated with a plasma jet at atmospheric pressure}

\author{
Sedef Dikmen* (D), Neslihan Şahin, Zafer Dikmen and Murat Tanışlı \\ Eskişehir Technical University, Faculty of Science, Department of Physics, 26470 Eskisehir, Turkey
}

\begin{abstract}
This study reports on the effects of dielectric barrier discharge-like (DBD-like) plasma jet treatment at atmospheric pressure on Ag cation-exchanged clinoptilolite. In the plasma treatment process, argon plasma was applied to the surface of pellet samples prepared with Ag-clinoptilolite. After DBD-like plasma jet treatment for 30 and $60 \mathrm{~min}$, remarkable colour changes were observed in the pellet samples. These changes indicate that the DBD-like plasma jet application led to the successful reduction of $\mathrm{Ag}^{+}$to its metallic forms, which was further confirmed by the results of ultraviolet-visible diffuse reflectance spectroscopy. The structural, composition and morphological properties of the DBD-like plasma jet-treated samples were characterized using Fourier-transform infrared (FTIR) spectroscopy, X-ray diffraction (XRD), scanning electron microscopy and energy-dispersive X-ray analyses, and they were compared to the untreated Ag-clinoptilolite. The DBD-like plasma jet treatment caused no detectable structural changes in clinoptilolite within the analytical limitations of the methods used. The FTIR spectra show that the plasma treatment causes discharge-induced functional changes in the hydroxyl stretching region. The peaks appearing in the XRD patterns confirmed the reduction of $\mathrm{Ag}^{+}$to $\mathrm{Ag}^{0}$ after exposure to the plasma. The present study indicates that the reduction of $\mathrm{Ag}^{+}$cations to their metallic forms can be performed successfully using the proposed method without collapsing the crystal structure of the Ag-clinoptilolite.
\end{abstract}

Keywords: Ag-exchanged clinoptilolite, characterization, DBD-like plasma jet, FTIR, SEM, UV-Vis DRS, XRD

(Received 7 March 2020; revised 5 October 2020; Accepted Manuscript online: 15 October 2020; Editor: George E. Christidis)

Zeolites are important crystalline micro- and meso-porous materials (Schwanke et al., 2017). They represent a group of naturally occurring hydrous aluminosilicate minerals with a cage-like crystal structure that can be synthesized in the laboratory (Altare et al., 2007). The structural properties of zeolites make them unique among inorganic materials. They have many applications in industry due to their high porosity, chemical stability, specific active sites, ion-exchange capacity and large specific surface area (Gottardi \& Galli, 1985). Despite the abundance and low cost of natural zeolites, they have been less preferred than expensive synthetic zeolites because of their variable physical-chemical properties and impure mineralogical compositions. Because the cost of these synthetic porous materials is significant, research has focused on studies that deal with the modification of natural zeolites for various potential applications. Applications in catalysis and adsorption generally require an additional modification of the zeolite, such as dealumination or ion exchange (Tsitsishvili \& Andronikashvili, 1992).

Zeolites possess a net negative charge due to the isomorphic substitutions of $\mathrm{Si}^{4+}$ by $\mathrm{Al}^{3+}$ in the tetrahedral sites. This residual negative charge is balanced by the presence of exchangeable cations $\left(\mathrm{Na}^{+}, \mathrm{K}^{+}, \mathrm{Ca}^{2+}\right.$ and $\left.\mathrm{Mg}^{2+}\right)$ in the cages, which allows excellent performance in terms of thermal stability, acid

${ }^{\star}$ E-mail: sdikmen@eskisehir.edu.tr

Cite this article: Dikmen S, Şahin N, Dikmen Z, Tanışlı M (2020). Characterization of Ag-exchanged clinoptilolite treated with a plasma jet at atmospheric pressure. Clay Minerals 55, 238-247. https://doi.org/10.1180/clm.2020.33 resistance, etc., depending on the cationic composition (Tsitsishvili \& Andronikashvili, 1992; Bertetti \& Pabalan, 2001). Due to their variable physicochemical properties, zeolites have been exploited in large-scale industrial applications such as adsorption/separation, ion exchange, molecular sieving and catalysis (Gottardi \& Galli, 1985). In addition to these conventional uses, which have a significant economic impact on various sectors of industry, there are specific uses of zeolites in new emerging applications, including luminescence, electricity, magnetism, microelectronics and biomedical processes. Recent studies have revealed that cation-exchange modification of natural zeolites with transition metals such as silver, zinc, copper, etc., also provides interesting pharmaceutical properties (Hotta et al., 1998; Rivera-Garza, 2000; Top \& Ulku, 2004; Akhigbe et al., 2014; Demirci et al., 2014; Milenkovic et al., 2017; Youssefa et al., 2019; Dutta \& Wang, 2019; Hubner et al., 2020).

The use of silver, which has antimicrobial properties in the form of $\mathrm{AgNO}_{3}$, dates back to ancient times. Today, the unique antibacterial activity of silver means that it is used in various applications, such as common consumer products and even in complicated medical devices. However, $\mathrm{AgNO}_{3}$ is not suitable for direct usage. Recently, research has been carried out on supporting materials for silver ions, which, in turn, will form stable structures that are resistant to atmospheric oxidation and have long-lasting antibacterial properties. Zeolites have been considered as potential candidates for delivering the properties above as cation carriers, and their porous structure allows for slow Ag release (Tosheva et al., 2017; Dutta \& Wang, 2019). The 
Ag-exchanged zeolite exhibits greater bactericidal activity compared to zeolites containing other transition metals such as $\mathrm{Cu}^{+}$ and $\mathrm{Zn}^{2+}$ (Top \& Ulku, 2004).

Modification of porous materials similar to zeolites with metal ions is also known and has many applications (Zhao et al., 2007; Wdowin et al., 2014; Čapková et al., 2016; Cisneros et al., 2019; Kennedy et al., 2019). Most of these modifications are performed at high pressure and/or temperature and with the addition of hazardous reagents, which raise their cost and may also be harmful to the environment. The high-temperature conditions and longlasting reduction processes often result in the aggregation of metal ions, reducing their efficiency. Recently, plasma technology, which provides energy-source savings, uses limited amounts of water and is environmentally safe, has attracted attention because of its advantages in comparison to traditional modification methods; this is important for the prevention of pollution.

Previous studies have focused on the use of various plasma applications in the surface modification of clays and zeolites (Djowe et al., 2013; Yavuz \& Saka, 2013; Şahin et al., 2015; Valesco-Maldonado et al., 2018; Wahono et al., 2019). On the other hand, there are few published studies on metal ion-loading onto porous materials such as zeolites that reduce these ions to metal atoms or clusters/nanoparticles using various plasma techniques. Rodríguez-Méndez et al. (2017) used pulsed dielectric barrier discharge (DBD) as a simple and economical way to produce silver nano- and micro-particles from Ag-zeolite. Osonio \& Vasquez (2018) proposed $13.56 \mathrm{MHz}$ radiofrequency plasma as an efficient method in the reduction of silver ions to sodium zeolite samples. As the plasma contains electrons, positive and negative ions, reactive radicals and excited and neutral species, it might lead to a rapid reduction of metal ions (Liu et al., 2014). The ion-exchange method is efficient at incorporating $\mathrm{Ag}^{+}$cations within the cavities of zeolites, and plasma treatment may tune surface characteristics such as roughness and wettability for biomedical applications (Taaca et al., 2020). Among the desirable surface properties are roughness and high wettability, which improve the bimolecular affinity to polar molecules (Taaca et al., 2020). Plasma technology is green and includes fast and simple methodologies for the preparation of metal nanoparticles without the need for any chemical reagents (Valesco-Maldonado et al., 2018; Osonio \& Vasquez, 2018; Di et al., 2019).

Based on the relative energies of the electrons, ions, radicals and neutral and excited species, the plasmas used for modification can be classified as thermal plasmas and non-thermal plasmas (or cold plasmas). In the non-thermal plasmas, the energy of electrons is greater than that of heavy particles. Therefore, they may promote chemical reactions at a lower temperature. Recently, non-thermal atmospheric-pressure plasma jets (APPJs) have been applied in various industrial processes, the surface modification of polymers, molecular modification, sterilization and biomedical devices (Araya et al., 2007; Junkar et al., 2011; Mozetic \& Vratnica, 2011; Kostov et al., 2014; Liu et al., 2014; Tanışlı et al., 2016, 2017, 2018). Remarkably, the use of atmosphericpressure plasma systems in clays and zeolites is a new approach. In these systems, it is not necessary to control the pressure of the surrounding gas atmosphere without vacuum equipment. Therefore, they are quite easy to construct.

Dielectric-free electrodes, DBD, DBD-like and single-electrode plasma jets are well-known APPJs. The advantage of DBD systems is that there is no risk of arcing between the object and the dielectrics, regardless of the closeness to the end of the discharge tube. Depending on whether the material applied is conductive or not, there is a risk of arcing in applications using DBD-like plasma jet systems. However, in these systems, more power can easily be given to the plasma. If the arcing is prevented, their use carries many advantages (Lu et al., 2012). DBD-like plasma jets have been applied to samples using various gases such as helium (He), argon (Ar), oxygen $\left(\mathrm{O}_{2}\right)$ and gas mixtures (Junkar et al., 2011; Lu et al., 2012; Kawasaki et al., 2013; Chu \& Lu, 2014; Lu et al., 2019). Compared with other gases, argon ionizes easily, and therefore low levels of energy are generally sufficient to create argon plasma. Therefore, it is easier to generate non-thermal plasmas at atmospheric pressure with argon than with other gases.

This study attempts to build on the work of previous screening studies of this type (Djowe et al., 2013; Yavuz \& Saka, 2013; Sahin et al., 2015; Čapková et al., 2016; Fouodjouo et al., 2017; Taaca \& Vasquez, 2017; Osonio \& Vasquez, 2018; Valesco-Maldonado, 2018; Di et al., 2019; Wahono et al., 2019; Taaca et al., 2020) and focuses on understanding the influence of DBD-like $\mathrm{Ar}$ plasma jets on the properties of Ag-exchanged clinoptilolite using structural and spectroscopic characterization. The Ar plasma may reduce the $\mathrm{Ag}^{+}$metal ions present in the pores and channels of Ag-clinoptilolite, as was further confirmed by ultraviolet-visible diffuse reflectance spectroscopy (UV-Vis DRS). The Ar plasma was applied to the surfaces of pellet samples prepared with Ag-clinoptilolite powder.

\section{Materials and methods}

\section{Materials}

A natural zeolitic tuff sample from a sedimentary deposit in the Gördes region (western Anatolia, Turkey) was supplied by Rota Mining Corporation. After grinding and screening, the $<63 \mu \mathrm{m}$ fraction was separated for this study.

In a previous study (Dikmen \& Yorukogullari, 2011), the main mineral constituent was estimated by semi-quantitative $\mathrm{X}$-ray diffraction (XRD) analysis as clinoptilolite, an intermediate type of the isomorphous series heulandite-clinoptilolite end-members (Gottardi \& Galli, 1985). The physical properties of the natural clinoptilolite are listed in Table 1 . The $\mathrm{SiO}_{2} / \mathrm{Al}_{2} \mathrm{O}_{3}$ ratio and oxide percentages (Table 2) were determined by X-ray fluorescence spectroscopy (Rigaku ZSX Primus). The Si/Al ratio of the sample is $\sim 5.5$, which is within the range 4.0-5.5, typical for clinoptilolite (Tsitsishvili \& Andronikashvili, 1992).

Silver nitrate $\left(\mathrm{AgNO}_{3} ; 99.0 \%\right.$ purity, locally sourced) was used to prepare Ag-clinoptilolite. $\mathrm{HCl}$ (Sigma-Aldrich) and $\mathrm{NaCl}$ (Carlo Erba) were of analytical grade. Deionized water was obtained from a Milli-Q purification system.

\section{Experimental}

\section{Preparation of Ag-clinoptilolite}

The Ag-exchanged form of clinoptilolite was prepared by the ion-exchange method according to Osonio \& Vasquez (2018). First, the clinoptilolite samples were mixed in $1 \mathrm{M} \mathrm{HCl}$ solution with a magnetic stirrer for $24 \mathrm{~h}$ at room temperature $\left(25 \pm 1^{\circ} \mathrm{C}\right)$ at a solid-to-liquid ratio of 1:100, washed with deionized water until $\mathrm{Cl}^{-}$-free $\left(\mathrm{AgNO}_{3}\right.$ test $)$ and dried overnight at $100^{\circ} \mathrm{C}$. After drying, the clinoptilolite was stirred in $0.1 \mathrm{M} \mathrm{NaCl}$ solution at room temperature for $24 \mathrm{~h}$ and washed repeatedly with deionized water until $\mathrm{Cl}^{-}$-free $\left(\mathrm{AgNO}_{3}\right.$ test). Subsequently, the Na-clinoptilolite was dried overnight at $100^{\circ} \mathrm{C}$ and was dispersed 
Table 1. Mineralogical composition and some physical properties of natural clinoptilolite (after Dikmen \& Yorukogullari, 2011).

\begin{tabular}{lr}
\hline \multicolumn{2}{c}{ Mineralogical content } \\
\hline Clinoptilolite (\%) & 90.5 \\
Feldspar (\%) & 3.8 \\
Quartz (\%) & 4.3 \\
Muscovite (\%) & 1.4 \\
\hline \multicolumn{1}{c}{ Physical properties } \\
\hline & \\
\hline Density ( $\mathrm{g} \mathrm{cm}^{-3}$ ) & 2.16 \\
Surface area (BET method; $\left.\mathrm{m}^{2} \mathrm{~g}^{-1}\right)$ & 48.10 \\
Average pore width (DR method; $\mathrm{nm})$ & 9.70 \\
Pore volume $\left(\mathrm{cm}^{3} \mathrm{~g}^{-1}\right)$ & 0.044 \\
\hline
\end{tabular}

$\mathrm{BET}=$ Brunauer-Emmett-Teller; DR = Dubinin-Radushkevich.

in $0.1 \mathrm{M} \mathrm{AgNO}_{3}$ solution to obtain Ag-clinoptilolite by $\mathrm{Ag}^{+}$-for- $\mathrm{Na}^{+}$exchange. The ion-exchange process was performed with a solid-to-liquid phase ratio of 1:100 at room temperature for $24 \mathrm{~h}$ by mechanical stirring in darkness to avoid reduction of $\mathrm{Ag}^{+}$ to $\mathrm{Ag}^{0}$. Subsequently, the Ag-clinoptilolite was washed with deionized water until free of salts, dried at $50^{\circ} \mathrm{C}$ overnight and stored in darkness. The Ag-clinoptilolite powder was pressed into a $13 \mathrm{~mm}$-diameter, $1 \mathrm{~mm}$-thick pellet by applying $5 \mathrm{t}$ of pressure using a uniaxial hydraulic press. The pellets were kept in a dark vial at room temperature for plasma treatment.

\section{Plasma jet treatment of Ag-clinoptilolite}

A plasma jet generated by a DBD-like system was used for the plasma treatments. The DBD-like plasma jet was produced in a horizontal quartz tube using a high-voltage AC power supply (Fig. 1). The length and outer and inner diameters of the quartz tube were $15,0.52$ and $0.41 \mathrm{~cm}$, respectively. The quartz tube contains the $17.0 \mathrm{~cm}$-long electrical tungsten electrode and the grounded electrode made of disc-shaped aluminium with a diameter of $3.6 \mathrm{~cm}$ and a thickness of $0.42 \mathrm{~cm}$. Argon gas was sent through the quartz tube to obtain plasma. The $\mathrm{Ar}$ gas flow rate was fixed at $4 \mathrm{~L} \mathrm{~min}^{-1}$ and was controlled with an $\mathrm{M}+\mathrm{W}$ Instruments GmbH Mass-Stream D6300 series flowmeter. The applied voltage and frequency of the power supply were $10 \mathrm{kV}$ and $20 \mathrm{kHz}$, respectively.

\section{Material characterization}

After completion of the plasma treatment for 30 and $60 \mathrm{~min}$, the morphological, composition and structural changes of the samples were analysed using various techniques. The reduction of $\mathrm{Ag}^{+}$to $\mathrm{Ag}^{0}$ after exposure to the Ar plasma was monitored via colour change in the pellets, because the shade of the pellets may be associated with the reduced Ag metallic forms. Fine powder samples were taken using a spatula from the dark grey shaded areas of the pellets for all analyses.

The UV-Vis DRS spectra were recorded on an UV-Vis Shimadzu 2600 spectrophotometer with a diffuse reflectance attachment. The background spectrum was recorded at room temperature with a blank glass plate and then the samples were placed onto the glass to record the UV-Vis DRS spectra over the range of $220-400 \mathrm{~nm}$.

The Fourier-transform infrared (FTIR) spectra were recorded on a Perkin Elmer 100 FTIR spectrometer in the range 4000$400 \mathrm{~cm}^{-1}$, with a resolution of $4 \mathrm{~cm}^{-1}$ over an average of 100 scans. Approximately $1.5 \mathrm{mg}$ samples were diluted in analytical-grade
Table 2. Chemical composition of natural and Ag-clinoptilolite.

\begin{tabular}{lcc}
\hline & \multicolumn{2}{c}{ Percentage by mass } \\
\cline { 2 - 3 } Oxide components & Natural clinoptilolite & Ag-clinoptilolite \\
\hline $\mathrm{SiO}_{2}$ & 73.57 & 79.44 \\
$\mathrm{Al}_{2} \mathrm{O}_{3}$ & 13.33 & 10.08 \\
$\mathrm{CaO}$ & 5.15 & 0.61 \\
$\mathrm{MgO}$ & 1.46 & 0.47 \\
$\mathrm{Fe}_{2} \mathrm{O}_{3}$ & 1.21 & 1.23 \\
$\mathrm{~K}_{2} \mathrm{O}$ & 0.90 & 3.20 \\
$\mathrm{Na}_{2} \mathrm{O}$ & 0.84 & 0.16 \\
$\mathrm{TiO}_{2}$ & 0.40 & 0.07 \\
$\mathrm{MnO}$ & 0.03 & 0.02 \\
$\mathrm{Ag}_{2} \mathrm{O}$ & - & 2.64 \\
$\mathrm{LOI}$ & 3.11 & 2.08 \\
$\mathrm{Total}$ & 100 & 100 \\
\hline
\end{tabular}

LOI = loss on ignition.

$\mathrm{KBr}$ ( $200 \mathrm{mg}$ ) and pressed into discs before analysis. The XRD traces were obtained with a BRUKER D8 Advance diffractometer using $\mathrm{Cu}-K \alpha$ radiation $(\lambda=1.54059 \AA)$ in the $7.0-70.0^{\circ} 2 \theta$ range, with a scanning step of $0.02^{\circ}$ and a counting time of $4 \mathrm{~s}$ per step. The Cu-tube was operated at $40 \mathrm{kV}$ and $40 \mathrm{~mA}$. The changes in microstructure and the formation of Ag clusters were observed with a ZEISS Ultra Plus field emission scanning electron microscope (FE-SEM) after the plasma treatment.

\section{Results and discussion}

The chemical compositions of the Ag-clinoptilolite and natural clinoptilolite are shown in Table 2 . The natural clinoptilolite contains $\mathrm{Ca}^{2+}, \mathrm{Mg}^{2+}$ and $\mathrm{K}^{+}$as major extra-framework cations. In the structure, pores form negatively charged channels and cavities due to the imbalance caused by the substitution of $\mathrm{Si}^{4+}$ by $\mathrm{Al}^{3+}$. This negative charge is compensated by alkali or alkaline earth extraframework cations (i.e. $\mathrm{Na}^{+}, \mathrm{K}^{+}, \mathrm{Ca}^{2+}$; Gottardi \& Galli, 1985; Petrov, 1995; Hubner et al., 2020). Following the $\mathrm{Ag}^{+}$exchange, a significant portion of the original exchangeable cations in the natural clinoptilolite were replaced by $\mathrm{Ag}^{+}$(Table 2), in agreement with previous work (Lihareva et al., 2010; Unaldı et al., 2013; Kennedy et al., 2019). In addition, a small amount of $\mathrm{Fe}^{3+}$ was observed in both samples and did not affect $\mathrm{Ag}^{+}$exchange. In addition, the $\mathrm{Si} / \mathrm{Al}$ ratio of the $\mathrm{Ag}$-clinoptilolite was greater than the $\mathrm{Si} / \mathrm{Al}$ ratio of the original clinoptilolite, demonstrating that extraction of aluminium occurred during purification with $\mathrm{HCl}$ (Table 2).

The changes in the physical appearance of the pellets after plasma treatment for 30 and $60 \mathrm{~min}$ are shown in Fig. 2. The original colour of the pellet was close to white, and this turned to shades of dark grey after plasma exposure in accordance with previous studies on the fabrication of silver nanocomposites via plasma-assisted reduction or other synthesis methods (Shameli et al., 2010; Osonio \& Vasquez, 2018).

The UV-Vis DRS spectra for Ag-clinoptilolite subjected to various plasma treatment times and the spectrum of the untreated Ag-clinoptilolite are shown in Fig. 3. The spectrum of Ag-clinoptilolite shows a peak at $303 \mathrm{~nm}$, in agreement with previous studies. The UV-Vis DRS spectra of zeolitic-rich tuffs containing primarily clinoptilolite and its silver-modified forms are used to determine the states of silver in the extra-framework sites (Concepción-Rosabal et al., 2005; Rodríguez-Iznaga et al., 2011; Chmielewská et al., 2014; Suligoj et al., 2020). After the 
(a)

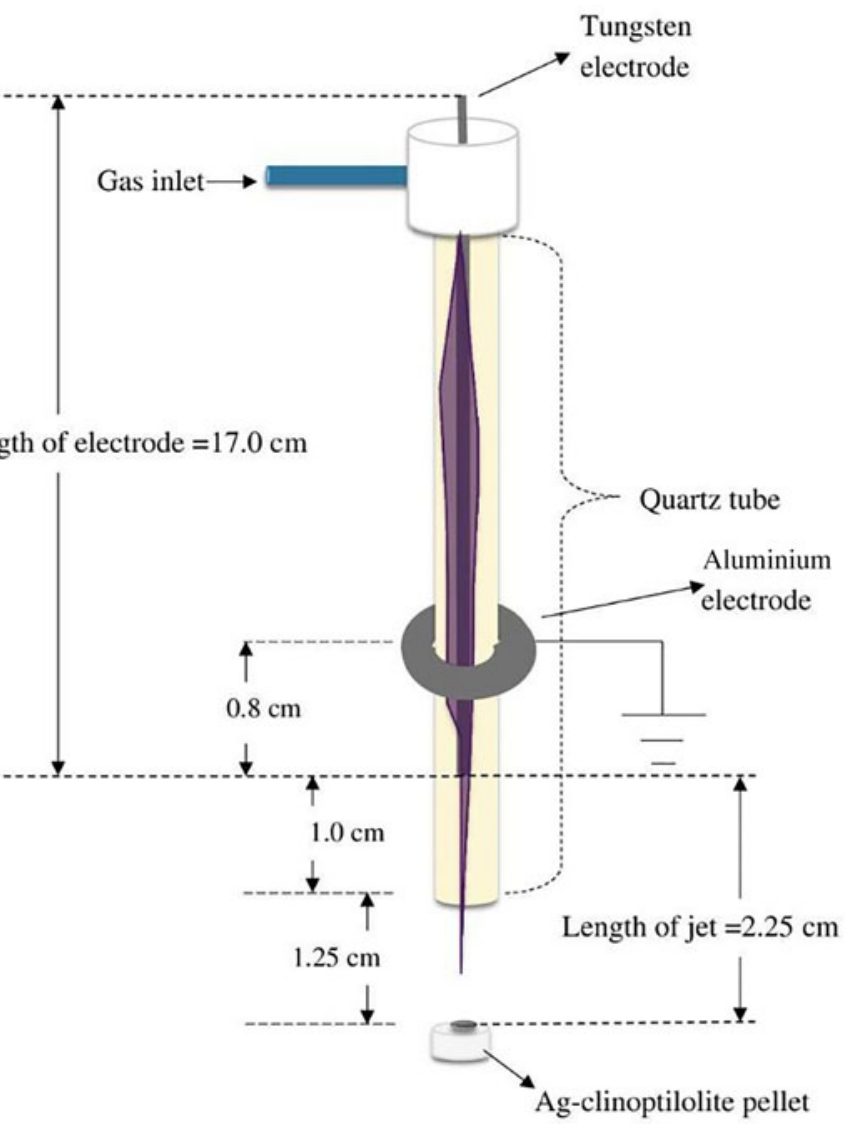

(b)

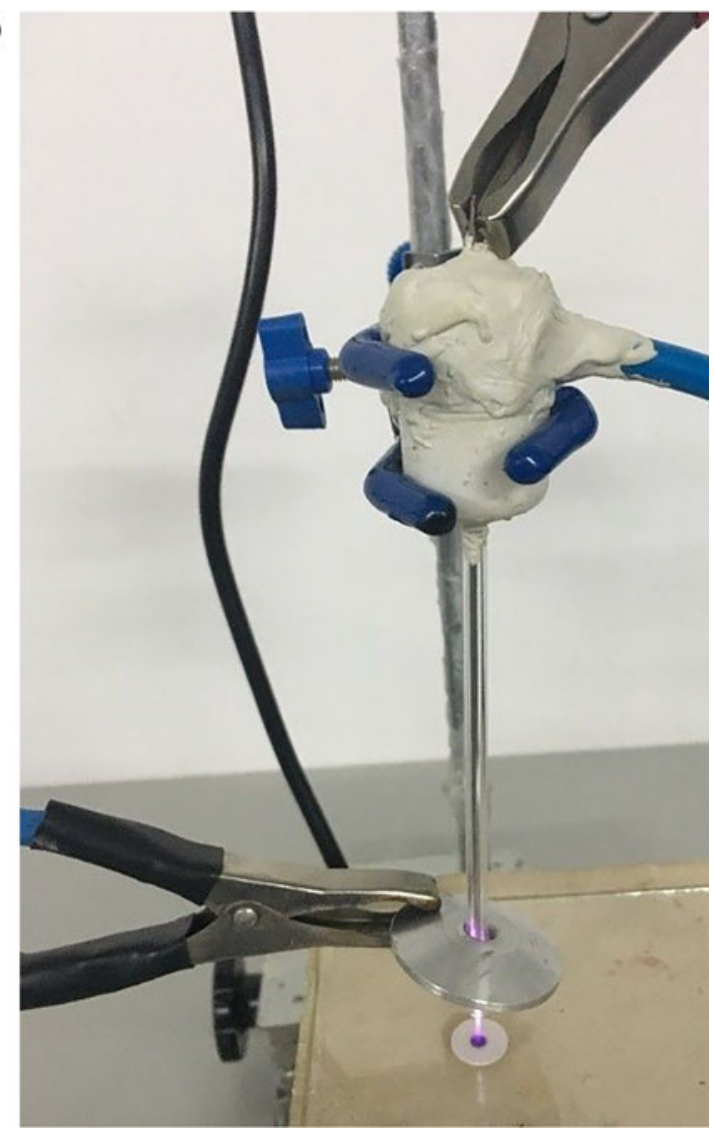

Fig. 1. (a) Experimental setup and (b) image of a DBD-like plasma jet.

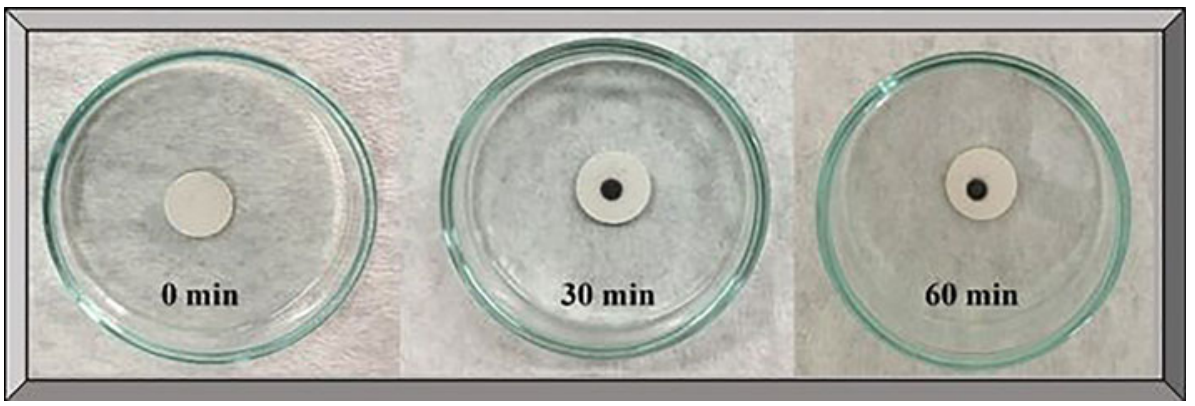

Fig. 2. Photograph of an untreated Ag-clinoptilolite pellet compared to the Ag-clinoptilolite pellets treated with plasma for 30 and $60 \mathrm{~min}$.
DBD-like plasma jet application, new absorption peaks centred at 325 and $370 \mathrm{~nm}$ appeared. The peak centred at $370 \mathrm{~nm}$ showed a cluster of metallic Ag on the external surface of the clinoptilolite framework. The peak at $325 \mathrm{~nm}$ is related to Ag clusters, as shown in previous work. Hence, eight-atom Ag clusters in mordenite absorb at 295 and $325 \mathrm{~nm}$ (Bogdanchikova et al., 1999), while the UV-Vis DRS spectra of Ag-clinoptilolite reduced to Ag clusters at various temperatures showed absorbance peaks at 325 and $290 \mathrm{~nm}$, related to $\mathrm{Ag}^{0}$ and $\mathrm{Ag}^{+}$clusters, respectively (Concepción-Rosabal et al., 2005). Silver clusters with $<10$ atoms related to these peaks are larger than the diameter of clinoptilolite channels (Chmielewská et al., 2003). Thus, it is suggested that the DBD-like plasma jet application yields small Ag clusters, in agreement with previous work (Chmielewská et al., 2003; Zaarour et al., 2014; Skiba \& Vorobyova, 2018; Gonçalves et al., 2019; Taaca et al., 2020).
Recently, a mechanism related to the plasma reduction of metal ions introduced into porous structures has been proposed, which suggests a direct combination of the electrons generated in the plasma and the ions of the salt (i.e. $\mathrm{AgNO}_{3}$ ). In this stage, the metal ions perform as 'electron sinks' that capture electrons upon exposure to the plasma. The neutral atom $\left(\mathrm{Ag}^{0}\right)$ forms relatively stable Ag clusters with other $\mathrm{Ag}^{+}$ions. Then, the $\mathrm{Ag}$ clusters combine with electrons to form Ag nanoparticles. Another mechanism suggests a plasma-induced dissociation of water molecules physisorbed on the zeolitic structure, which generates hydrated electrons and hydrogen radicals that easily react with the metal ions in the structure (Chmielewská et al., 2003; Osonio \& Vasquez, 2018; Gonçalves et al., 2019).

The FTIR spectra of the untreated and plasma-treated Ag-exchanged clinoptilolite were compared with that of the original clinoptilolite (Fig. 4a-d). The spectrum of the natural 
Fig. 3. UV-Vis DRS absorption spectra of (a) untreated plasma Ag-clinoptilolite, (b) Ag-clinoptilolite treated with plasma for $30 \mathrm{~min}$ and (c) Ag-clinoptilolite treated with plasma for $60 \mathrm{~min}$. $\mathrm{Cln}=$ clinoptilolite.

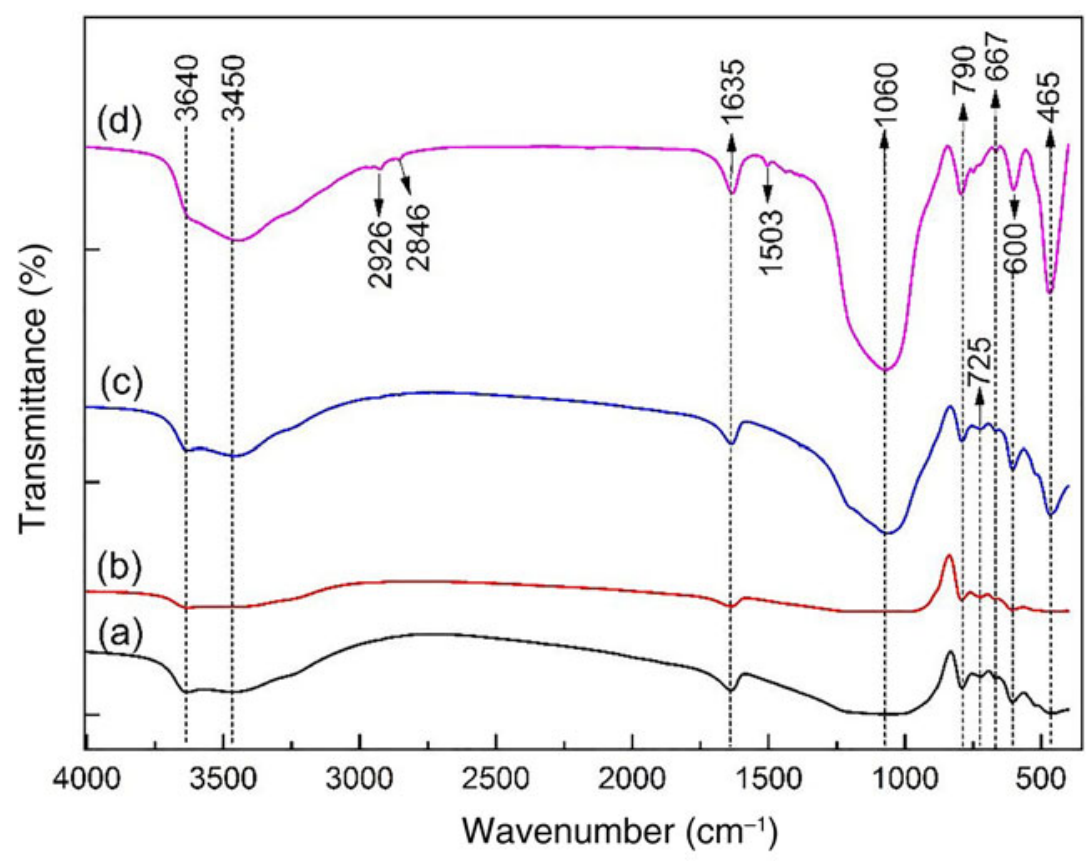

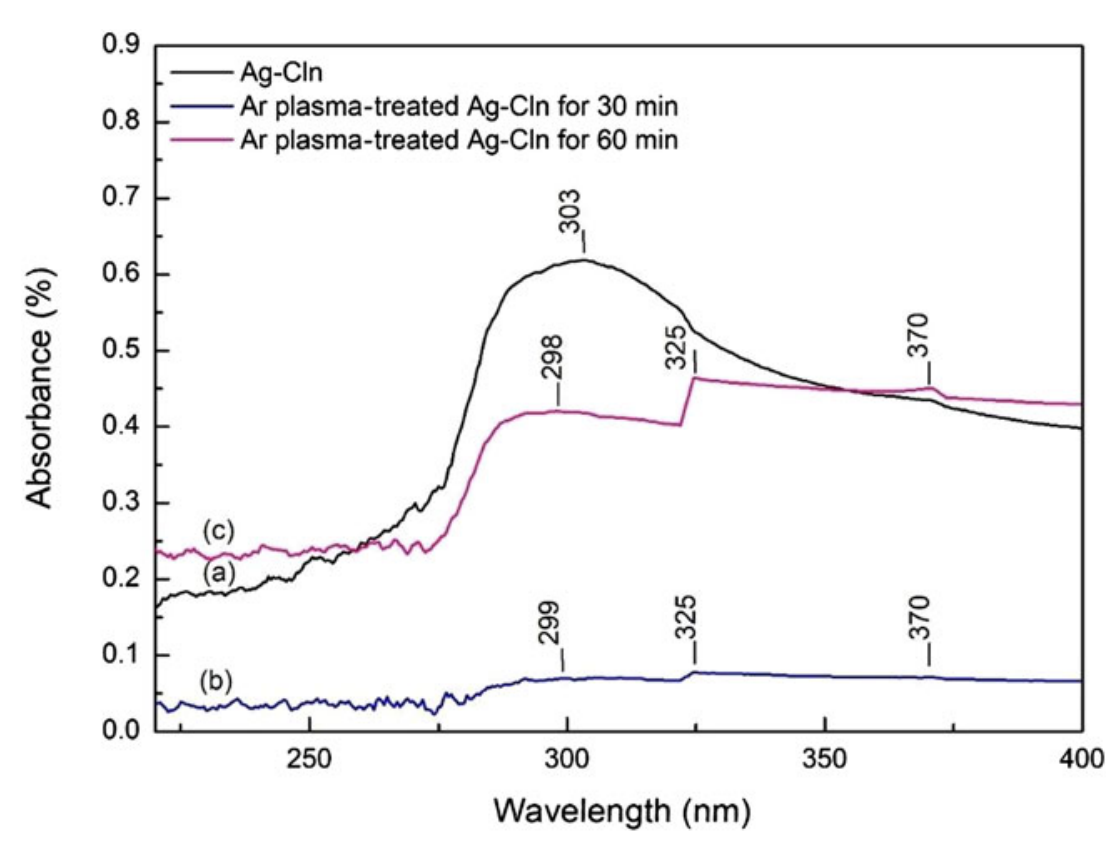

Fig. 4. FTIR spectra of (a) clinoptilolite, (b) untreated plasma Ag-clinoptilolite, (c) Ag-clinoptilolite treated with plasma for $30 \mathrm{~min}$ and (d) Ag-clinoptilolite treated with plasma for $60 \mathrm{~min}$. clinoptilolite sample is in accord with the clinoptilolite FTIR spectra reported in the literature (Breck, 1974; Pechar \& Rykl, 1981; Tsitsishvili \& Andronikashvili, 1992; Franus \& Dudek, 1999; Mozgawa, 2000; Auerbach et al., 2003; Korkuna et al., 2006; Doula, 2007; Elaiopoulos et al., 2010; Unald1 et al., 2013; Nikita \& Chervonny, 2016; Valesco-Maldonado et al., 2018). The broad bands at 3640 and $3450 \mathrm{~cm}^{-1}$ are attributed to asymmetric and symmetric $\mathrm{O}-\mathrm{H}$ stretching and the band at $1635 \mathrm{~cm}^{-1}$ is attributed to $\mathrm{O}-\mathrm{H}$ bending of physisorbed water. The prominent band centred at $\sim 1060 \mathrm{~cm}^{-1}$ corresponds to asymmetric T-O stretching vibrations $(\mathrm{T}=$ tetrahedral species $\mathrm{Al}, \mathrm{Si})$. The intense band in the $1040-1070 \mathrm{~cm}^{-1}$ region is due to $\mathrm{O}-\mathrm{Si}(\mathrm{Al})-\mathrm{O}$ bond vibrations in tetrahedra $\left(\mathrm{TO}_{4}\right)$ or aluminium- and silicon-oxygen bridges (Pechar \& Rykl, 1981). More specifically, an idealized clinoptilolite sample would give a band at $1060 \mathrm{~cm}^{-1}$ (Mozgawa, 2000; Nikita \& Chervonny, 2016). This band is associated with the $\mathrm{Al}$ and $\mathrm{Si}$ content in the crystalline framework of natural zeolites, and its position varies with the $\mathrm{Si} / \mathrm{Al}$ ratio. More specifically, an increasing number of tetrahedral $\mathrm{Al}$ atoms (i.e. a lower $\mathrm{Si} / \mathrm{Al}$ ratio) might shift the vibration mode to a lower frequency (Breck, 1974; Pechar \& Rykl, 1981; Rodriguez-Fuentes et al., 1998; Elaiopoulos et al., 2008). The bands at 790 and $465 \mathrm{~cm}^{-1}$ are assigned to the external symmetric $\mathrm{O}-\mathrm{T}-\mathrm{O}$ stretching modes and the bending of the bonds inside the $\mathrm{TO}_{4}$ units, respectively (Rodriguez-Fuentes et al., 1998; Doula, 2007). In the region of $700-500 \mathrm{~cm}^{-1}$, the bands at 667 and $600 \mathrm{~cm}^{-1}$ are due to four- or six-membered ring vibrations of $\mathrm{TO}_{4}$ units and stretching of the inter tetrahedral bonds typical of the ordered 


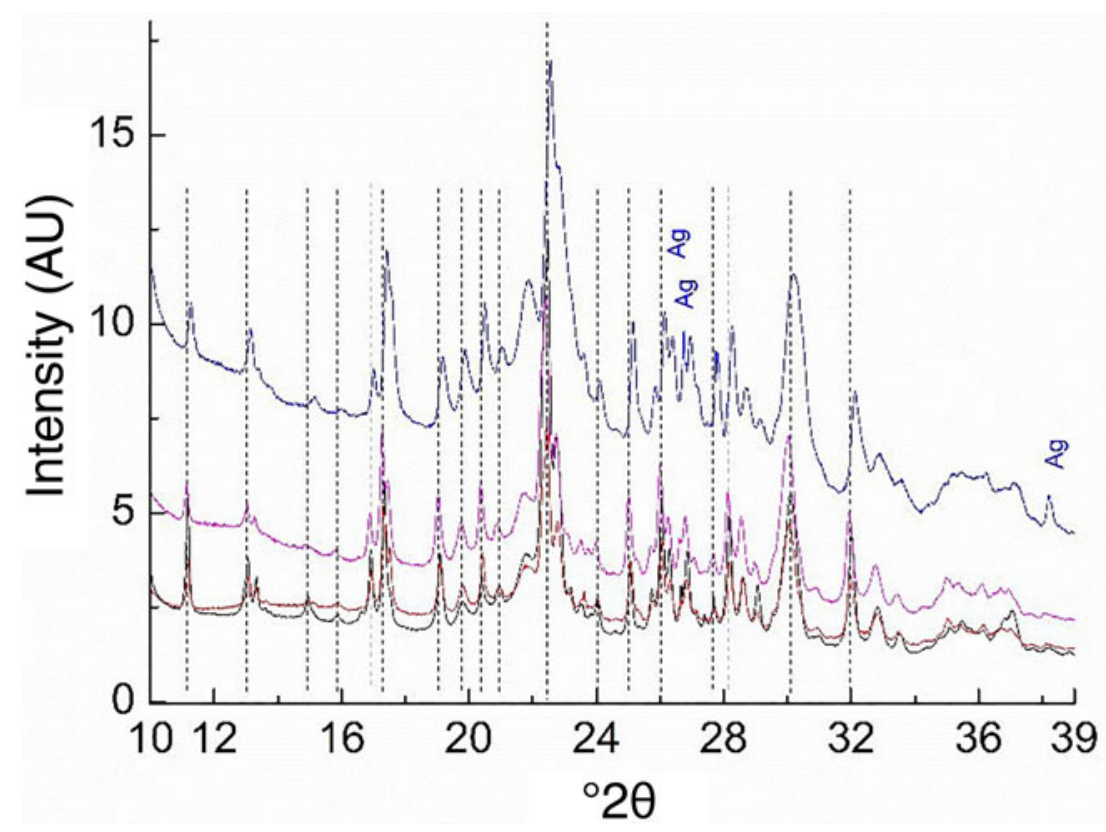

Fig. 5. XRD traces of clinoptilolite (black) and untreated Ag-clinoptilolite (red) compared to the Ag-clinoptilolite treated with plasma for $30 \mathrm{~min}$ (blue) and $60 \mathrm{~min}$ (pink).
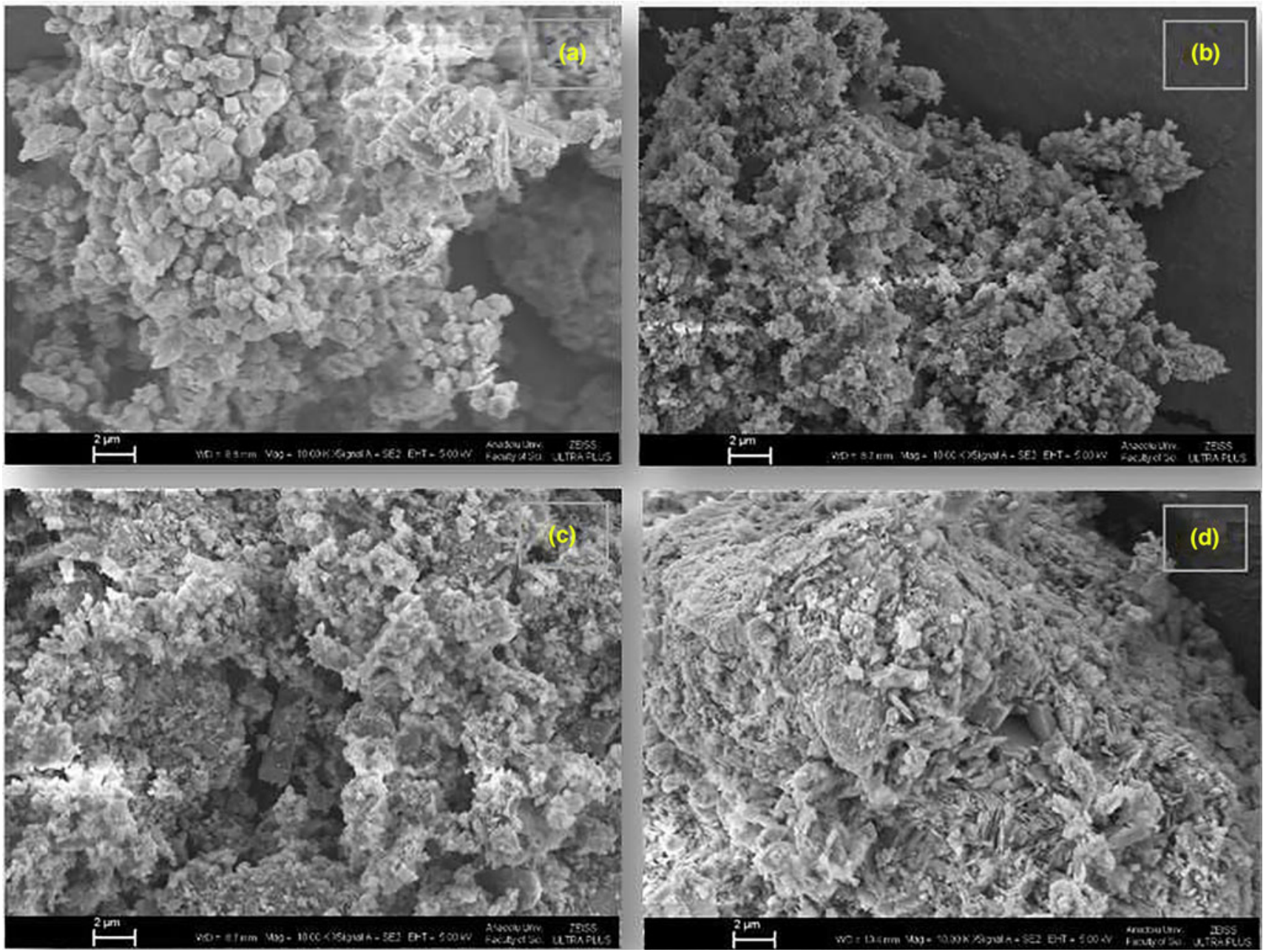

Fig. 6. SEM images of (a) clinoptilolite, (b) untreated Ag-clinoptilolite, (c) Ag-clinoptilolite treated with plasma for 30 min and (d) Ag-clinoptilolite treated with plasma for $60 \mathrm{~min}$. 
(a)

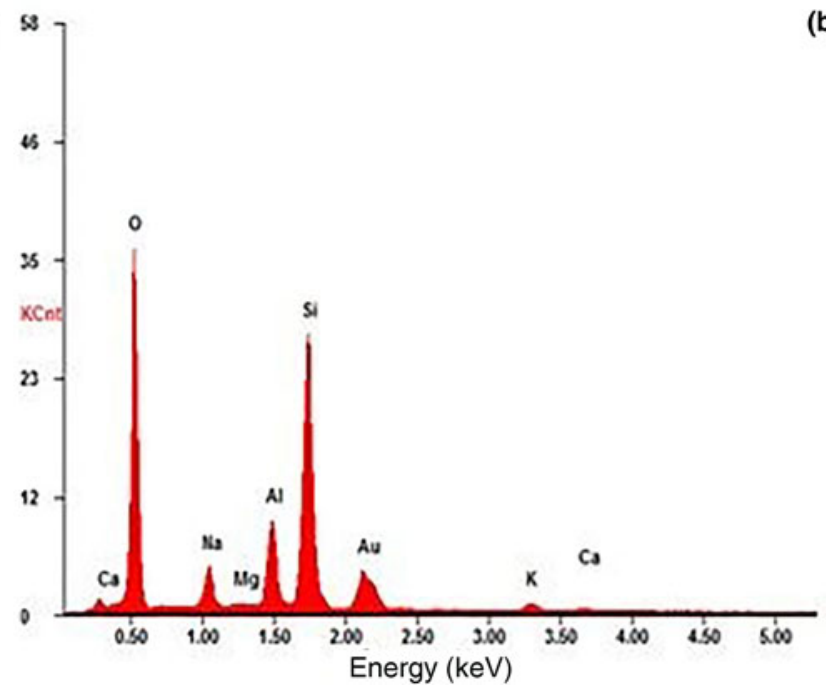

(b)

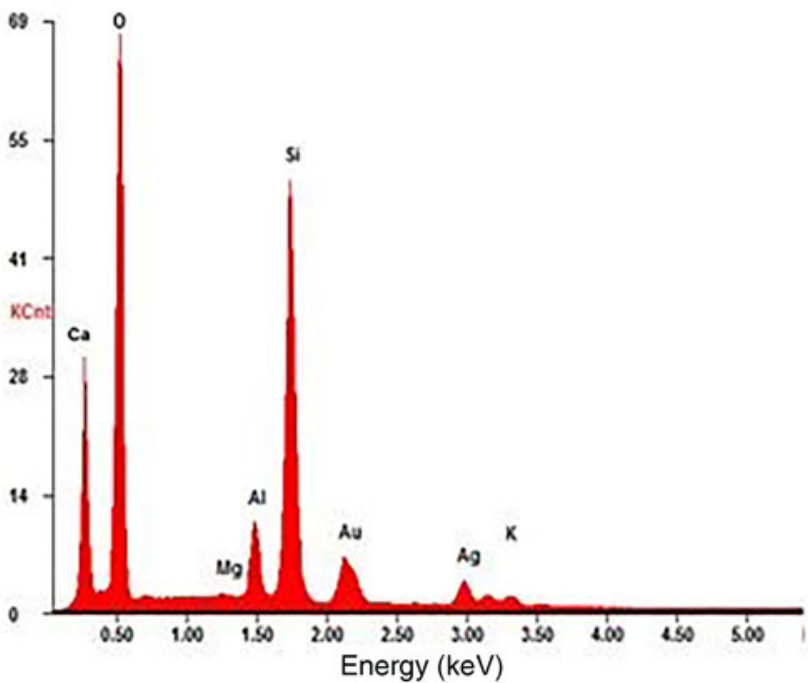

Fig. 7. EDX spectra of (a) clinoptilolite and (b) Ag-clinoptilolite treated with plasma for $60 \mathrm{~min}$.

crystal structure, respectively. The very weak band at $525 \mathrm{~cm}^{-1}$ is attributed to 'pore opening' (Mozgawa, 2000; Doula, 2007).

After the $\mathrm{Ag}^{+}$-exchange process, the FTIR bands occur at similar wavenumbers (Fig. 4b). The $\mathrm{Ag}^{+}$cations did not affect significantly the spectrum of clinoptilolite in the range of vibrations of the framework $\left(800-400 \mathrm{~cm}^{-1}\right)$ and T-O bonds $\left(1200-900 \mathrm{~cm}^{-1}\right)$. Hence, the clinoptilolite lattice is largely unaffected by the $\mathrm{Ag}^{+}$ cations due to the low concentration of $\mathrm{AgNO}_{3}$. Kennedy et al. (2019) and Unaldi et al. (2013) reported two bands at 253 and $206 \mathrm{~cm}^{-1}$ corresponding to Ag-O stretching vibrations (i.e. outside the spectral range of the present study). Therefore, it cannot be verified whether Ag complexes have been formed following $\mathrm{Ag}^{+}$cation exchange. Exposure to Ag-clinoptilolite through plasma discharge induced functional changes in the hydroxyl stretching region (Fig. 4c,d). The narrowing and slight shifting of the Ag-clinoptilolite band at $3640 \mathrm{~cm}^{-1}$ (Fig. 4c) may be attributed to the interaction between the hydroxyl group of adsorbed water on clinoptilolite and the Ag metallic forms. The increase in the absorbance intensity of the $-\mathrm{OH}$ stretching band might have contributed to the significant increase in the polar surface free energy of the plasma-modified Ag-exchanged zeolite (Taaca \& Vasquez, 2017). The interaction is more visible in the framework region, indicating that the structure of the clinoptilolite might have been affected by the plasma treatment. More specifically, the band intensity of the internal tetrahedral bonds $\left(600 \mathrm{~cm}^{-1}\right)$ and the external symmetric O-T-O stretching vibrations $\left(790 \mathrm{~cm}^{-1}\right)$ increased. A similar observation was reported after treatment of an Ag-zeolite (AgZ) composite at a radiofrequency of $13.56 \mathrm{MHz}$ (Osonio \& Vasquez, 2018). Non-thermal plasma modification of smectites affected the framework region $\left(530\right.$ and $\left.473 \mathrm{~cm}^{-1}\right)$ to a lesser degree compared to the hydroxyl stretching region (4000$2600 \mathrm{~cm}^{-1}$ ) (Djowe et al., 2013). Finally, the sample exposed to plasma for $60 \mathrm{~min}$ showed a new band at $\sim 1500 \mathrm{~cm}^{-1}$. This may be due to excited species produced by argon plasma treatment in this time interval.

The XRD traces of the clinoptilolite, Ag-clinoptilolite and Ar plasma-treated Ag-clinoptilolite for 30 and $60 \mathrm{~min}$ are shown in Fig. 5. The presence of clinoptilolite was confirmed by characteristic diffraction lines at $9.88^{\circ} 2 \theta\left(d_{020}=8.955 \AA\right), 11.19^{\circ} 2 \theta$ $\left(d_{200}=7.899 \AA\right), 17.37^{\circ} 2 \theta\left(d_{111}=5.099 \AA\right), 22.43^{\circ} 2 \theta\left(d_{400}=3.959 \AA\right)$, $26.06^{\circ} 2 \theta\left(d_{\overline{2} 22}=3.416 \AA\right), 30.04^{\circ} 2 \theta\left(d_{151}=2.971 \AA\right)$ and $\left.32.75^{\circ} 2 \theta\right)$ $\left(d_{\overline{2} 61}=2.731 \AA\right)$. After ion exchange with $0.1 \mathrm{M} \mathrm{AgNO}_{3}$, the overall XRD trace was substantially preserved; however, significant variations in the peak intensity were observed compared to the natural clinoptilolite. The significant decrease in intensity of the (020), (200) and (400) diffraction lines after ion exchange is due to the nature, location and amount of extra-framework species (Petrov, 1995; Concepción-Rosabal et al., 2005; Dimova et al., 2011; Hubner et al., 2020). The 020 diffraction line at $9.88^{\circ} 2 \theta$ almost disappeared (Fig. 5) due to modifications in the crystal form. Previous research has reported similar XRD results for clinoptilolite exchanged with transition metal cations (Dimova et al., 2011; Unaldı et al., 2013; Kennedy et al., 2019). The intensity of the (020) peak of Ag-exchanged clinoptilolite varies probably because it is strongly related to the extraframework species located in the mirror plane perpendicular to the $b$-axis of the monoclinic structure of clinoptilolite (Hubner et al., 2020).

Before plasma treatment, no obvious diffraction peaks belonging to metallic silver were detected in the XRD traces. After the plasma treatment, new peaks corresponding to $\mathrm{Ag}^{+}$metal ions in the Ag-clinoptilolite sample appeared at $26.42^{\circ} 2 \theta, 28.03^{\circ} 2 \theta$ and $38.20^{\circ} 2 \theta$, corresponding to the (111), (210) and (111) planes of a cubic face-centred lattice of silver, confirming that a silver crystalline structure might have been produced by applying a plasma jet. In addition, most of the clinoptilolite peaks shifted slightly to higher angles after plasma treatment, especially after $30 \mathrm{~min}$ of treatment. Moreover, the characteristic XRD peaks of Ag-clinoptilolite exhibit broadening after exposure to Ar plasma (Fig. 5). Similar changes induced by plasma treatment of the structure of the natural zeolite, Ag-zeolite, bentonite clay, etc., have been reported in previous studies (Djowe et al., 2013; Čapková et al., 2016; Osonio \& Vasquez, 2018; Valesco-Maldonado et al., 2018).

The effect of the plasma treatment on the morphological characteristics of Ag-clinoptilolite was examined by SEM (Fig. 6a-d). The Ag-clinoptilolite showed differences in surface morphology compared to clinoptilolite as a result of mechanical processes such as grinding and mixing. The surface of Ag-clinoptilolite (Fig. 6c,d) is more irregular than the surface of the original clinoptilolite (Fig. 6a,b). The average length of the tabular 
clinoptilolite crystals was $\sim 2.0 \mu \mathrm{m}$, and the thickness was between 0.5 and $2.0 \mu \mathrm{m}$. After plasma treatment for $60 \mathrm{~min}$, the cubic and thin platy forms present in the Ag-clinoptilolite might have been caused by the change in the surface charge of the particles, possibly due to the plasma treatment. The energy-dispersive X-ray (EDX) spectra provided semi-quantitative analysis of the $\mathrm{Ag}^{+}$ and other cations in the samples (Fig. 7a,b). The peaks at 3.0 and $3.2 \mathrm{keV}$ (Fig. $7 \mathrm{~b}$ ) are related to metallic silver binding energies, which is in accord with the literature (Rivera-Garza et al., 2000; Shameli et al., 2010; Copcia et al., 2011; Boschetto et al., 2012; Osonio \& Vasquez, 2018). Other peaks in the EDX spectra correspond to the binding energies of $\mathrm{Ca}, \mathrm{K}, \mathrm{Na}, \mathrm{Si}$ and $\mathrm{Al}$.

\section{Summary and conclusions}

A natural clinoptilolite from Turkey rich in $\mathrm{Ca}^{2+}, \mathrm{Mg}^{2+}$ and $\mathrm{K}^{+}$ with an $\mathrm{Al} / \mathrm{Si}$ ratio of 5.5 was successfully cation-exchanged with $\mathrm{Ag}$. The $\mathrm{Ag}^{+}$cations were incorporated within the cavities and/or channels of clinoptilolite. The effects of a DBD-like plasma jet at atmospheric pressure on the structural, composition and morphological properties of Ag-clinoptilolite were assessed using UV-Vis DRS, FTIR, XRD and SEM-EDX analysis. The plasma treatment for 30 and $60 \mathrm{~min}$ using Ar as the forming gas successfully reduced $\mathrm{Ag}^{+}$to its metallic form while maintaining the structure of clinoptilolite. The UV-Vis DRS results showed two absorption peaks at 325 and $370 \mathrm{~nm}$ related to $\mathrm{Ag}$ clusters. The absorption intensity of both peaks decreased with decreasing plasma treatment time. Before Ar plasma treatment, no obvious diffraction peaks belonging to a metallic silver were detected in the XRD traces, suggesting that silver ions were introduced in the Ag-clinoptilolite cages during the plasma treatment. The FTIR spectra show that exposure of Ag-clinoptilolite to the plasma discharge induced functional changes in the hydroxyl stretching region. The Ag-clinoptilolite exposed to plasma for 60 min showed a new band at $\sim 1500 \mathrm{~cm}^{-1}$, possibly due to excited species produced during the treatment, as was supported by SEM observations. The cubic and thin platy particles appeared on the Ag-clinoptilolite sample treated with plasma for $60 \mathrm{~min}$ due to the change in the surface charge of the particles, possibly due to exposure to gaseous discharges. The EDX spectra confirmed the formation of Ag clusters; however, as the oxygen content was still high, silver oxide might also be present. Based on the present investigation, the suggested method of plasma treatment may be effective, saving both energy and time.

Acknowledgements. The authors thank Prof Dr Güneş S. Kürkçüoğlu (Eskişehir Osmangazi University) for her support in the use of the FTIR spectrophotometer. The authors also thank Orhan Çetin of the technical personnel of the Ceramic Research Center of ESTU for the X-ray fluorescence analysis.

\section{References}

Akhigbe L., Ouki S., Saroj D. \& Lim X.M. (2014) Silver-modified clinoptilolite for the removal of Escherichia coli and heavy metals from aqueous solutions. Environmental Science and Pollution Research, 21, 10940-10948.

Altare R., Bowman R.S., Katz L.E., Kinney K.A. \& Sullivan E.J. (2007) Regeneration and long-term stability of surfactant-modified zeolite for removal of volatile organic compounds from produced water. Microporous and Mesoporous Materials, 105, 305-316.

Araya M., Yuji T., Watanabe T., Kashihara, J. \& Sumida Y. (2007) Application to cleaning of waste plastic surfaces using atmospheric non-thermal plasma jets. Thin Solid Films, 515, 4301-4307.
Auerbach S.M., Carrado K.A. \& Dutta P.K., editors (2003) Handbook of Zeolite Science and Technology. Marcel Dekker, New York, NY, USA, 1204 pp.

Bertetti F.P. \& Pabalan R. T. (2001) Cation-exchange properties of natural zeolites. Reviews in Mineralogy and Geochemistry, 45, 453-518.

Bogdanchikovaa N.E., Petranovskiia V.P., Machorro R.M., Sugic Y., Soto V.M. \& Fuentes S. (1999) Stability of silver clusters in mordenites with different $\mathrm{SiO}_{2} / \mathrm{Al}_{2} \mathrm{O}_{3}$ molar ratio. Applied Surface Science, 150, 58-64.

Boschetto D.A., Lerin L., Cansian R., Pergher S.B.C. \& Di Luccio M. (2012) Preparation and antimicrobial activity of polyethylene composite films with silver exchanged zeolite-Y. Chemical Engineering Journal, 204-206, 210-216.

Breck D.W. (1974) Zeolite Molecular Sieves: Structure, Chemistry, and Use. Wiley, New York, NY, USA, 784 pp.

Čapková P., Matoušek J., Rejnek J., Bendlová N., Pavlík J., Kormunda M. et al.. (2016) Effect of plasma treatment on structure and surface properties of montmorillonite. Applied Clay Science, 129, 15-19.

Chmielewská E. (2014) Environmental Zeolites and Aqueous Media. Examples of Practical Solutions. Bentham Science Publishers, Sharjah, UAE, 220 pp.

Chmielewská E., Jesenák K. \& Gáplovská K. (2003) Arsenate and chromate removal with cationic surfactant-loaded and cation-exchanged clinoptilolite-rich tuff $v s$ montmorillonite. Collection of Czechoslovak Chemical Communication, 68, 823-836.

Chu P.K. \& Lu X., editors (2014) Low Temperature Plasma Technology: Methods and Applications. CRC Press, Boca Raton, FL, USA, 493 pp.

Cisneros L., Gao F. \& Corma A. (2019) Nanocluster in zeolites. Adsorption of ethylene traces for fruit preservation ethylene adsorption. Microporous and Mesoporous Materials, 283, 25-30.

Concepción-Rosabal B., Rodriguez-Fuentes G., Bogdanchikova N., Boschc P., Avalosb M. \& Lara V.H. (2005) Comparative study of natural and synthetic clinoptilolites containing silver in different states. Microporous and Mesoporous Materials, 86, 249-255.

Copcia V.E., Luchian C., Dunca S., Bilba N. \& Hristodor C.M. (2011) Antibacterial activity of silver-modified natural clinoptilolite. Journal of Materials Science, 46, 7121-7128.

Demirci S., Ustaoglu Z., Yllmazer G.A., Sahin F. \& Bac N. (2014) Antimicrobial properties of zeolite-X and zeolite-A ion-exchanged with silver, copper, and zinc against a broad range of microorganisms. Applied Biochemistry and Biotechnology, 172, 1652-1662.

Di L., Li Z., Zhang X., Wang H. \& Fan Z. (2019) Reduction of supported metal ions by a safe atmospheric pressure alcohol cold plasma method. Catalysis Today, 337, 55-62.

Dikmen S. \& Yorukogullari E. (2011) Nitrate removal by hexadecyltrimethylammonium bromide-modified clinoptilolite. Asian Journal of Chemistry, 23, 2655-2659.

Dimova L., Petrov O., Kadiyski M., Lihareva N., Stoyanova-Ivanova A. \& Mikli V. (2011) Preparation and Rietveld refinement of Ag-exchanged clinoptilolite. Clay Minerals, 46, 205-212.

Djowe A.T., Laminsi S., Njopwouo D., Acayanka E. \& Gaigneaux E.M. (2013) Surface modification of smectite clay induced by non-thermal gliding arc plasma at atmospheric pressure. Plasma Chemistry and Plasma Processing, 33, 707-723.

Doula M.K. (2007) Synthesis of a clinoptilolite-Fe system with high Cu sorption capacity. Chemosphore 67, 731-740.

Dutta P. \& Wang B. (2019) Zeolite-supported silver as antimicrobial agents. Coordination Chemistry Reviews, 383, 1-29.

Elaiopoulos K., Perraki T. \& Grigoropoulou E. (2008) Mineralogical study and porosimetry measurement of zeolites from Scaloma area, Thrace, Greece. Microporous and Mesoporous Materials, 112, 441-449.

Elaiopoulos K., Perraki T. \& Grigoropoulou E. (2010) Monitoring the effect of hydrothermal treatments on the structure of a natural zeolite through a combined XRD, FTIR, XRF, SEM and $\mathrm{N}_{2}$-porosimetry analysis. Microporous and Mesoporous Materials, 134, 29-43.

Fouodjouo M., Fotouo-Nkaffo H., Lamins S., Cassini F.A., de Brito-Benetoli L.O. \& Debacher N.A. (2017) Adsorption of copper (II) onto Cameroonian clay modified by non-thermal plasma: characterization chemical equilibrium and thermodynamic studies. Applied Clay Science, 142, 136-144.

Franus A. \& Dudek K. (1999) Clay minerals and clinoptilolite from the variegated shales formation in the Skole Unit, Polish Flysch Carpathians. Geologica Carpathica, 50, 23-24. 
Gonçalves I.A., Barauna J., Cunha-Filho F.J., Chiavone-Filho O., Vitoriano J.O., Júnior C.A. \& Mota-Lima A. (2019) Reduction of aqueous $\mathrm{Ag}^{+}$steered by electrochemical plasma: Connecting the bulk $\mathrm{pH}$ variation with the reaction pathways for hydrated electrons. Journal of Brazilian Chemical Society, 30, 1252-1265.

Gottardi G. \& Galli E., editors (1985) Natural Zeolites. Springer-Verlag, Berlin, Germany, 412 pp.

Hotta M., Nakajima H., Yamamoto K. \& Aono M. (1998) Anti-bacterial temporary filling materials: the effect of adding various ratios of Ag-Zn-zeolite. Journal of Oral Rehabilitation, 25, 485-489.

Hubner P., Donati N., Quines L.K.M., Tessaro I.C. \& Marcilio N.R. (2020) Gelatin-based films containing clinoptilolite- $\mathrm{Ag}$ for application as wound dressing. Materials Science \& Engineering C, 107, 110215.

Junkar I., Cvelbar U. \& Lehocky M. (2011) Plasma treatment of biomedical materials. Materials Technology, 45, 221-226.

Kawasaki T., Hoketsu S., Morisaki H., Sato K., Baba H., Umeda S. et al.. (2013) Basic study on generation and sterilization of sheet type plasma jet-like DBD under atmospheric pressure. International Journal of Plasma Environmental Science \& Technology, 7, 26-30.

Kennedy D.A., Khanafer M. \& Tezel F.H. (2019) The effect of $\mathrm{Ag}^{+}$cations on the micropore properties of clinoptilolite and related adsorption separation of $\mathrm{CH}_{4}$ and $\mathrm{N}_{2}$ gases. Microporous and Mesoporous Materials, 281, 123133.

Korkuna O., Leboda R., Skubiszewska-Zieba J., Vrublevska T., Gunko V.M. \& Ryczkowski J. (2006) Structural and physicochemical properties of natural zeolites: clinoptilolite and mordenite. Microporous and Mesoporous Materials, 87, 243-254.

Kostov K.G., Nishime T.M.C., Castro A.H.R., Toth A. \& Hein L.R.O. (2014) Surface modification of polymeric materials by cold atmospheric plasma jet. Applied Surface Science, 314, 367-375.

Lihareva N., Dimova L., Petrov O. \& Tsvetanova Y. (2010) $\mathrm{Ag}^{+}$sorption on natural and Na-exchanged clinoptilolite from eastern Rhodopes, Bulgaria. Microporous and Mesoporous Materials, 130, 32-37.

Liu C.J., Zhao Y., Li Y., Zhang D.S., Chang Z. \& Bu X.H. (2014) Perspectives on electron-assisted reduction for preparation of highly dispersed noble metal catalysts. ACS Sustainable Chemistry \& Engineering, 2, 3-13.

$\mathrm{Lu}$ X., Laroussi M. \& Puech V. (2012) On atmospheric-pressure non-equilibrium plasma jets and plasma bullets. Plasma Sources Science and Technology, 21, 034005.

Lu X., Reuter S., Laroussi M. \& Liu D. (2019) Nonequilibrium Atmospheric Pressure Plasma Jets: Fundamentals, Diagnostics and Medical Applications. CRC Press, Boca Raton, FL, USA, 446 pp.

Milenkovic J., Hrenovic J., Matijasevic D., Niksic M. \& Rajic N. (2017) Bactericidal activity of $\mathrm{Cu}-, \mathrm{Zn}-$, and $\mathrm{Ag}$-containing zeolites toward $\mathrm{E}$. coli isolates. Environmental Science and Pollution Research, 24, 2027320281.

Mozetic M. \& Vratnica Z. (2011) Destruction of Bacillus stearothermophilus bacteria by weakly ionized low-pressure cold oxygen plasma, Vacuum, 85, 1080-1082.

Mozgawa W. (2000) The influence of some heavy metals cations on the FTIR spectra of zeolites. Journal of Molecular Structure, 555, 299-304.

Nikita V.C. \& Chervonny A.D. (2016) Infrared Spectroscopy of Minerals and Related Compounds. Springer, Cham, Switzerland, 1120 pp.

Osonio A.P. \& Vasquez M.R. Jr (2018) Plasma-assisted reduction of silver ions impregnated into a natural zeolite framework. Applied Surface Science, 432, 156-162.

Pechar F. \& Rykl D. (1981) Infrared spectra of natural zeolites of the stilbite group. Chemicke Zvesti, 35, 189-202.

Petrov O. (1995) Cation exchange in clinoptilolite: an X-ray powder diffraction analysis. Pp. 271-281 in: Natural Zeolites '93, Occurrence, Properties, Use (D.W. Ming \& F.A. Mumpton, editors). International Committee on Natural Zeolites, New York, NY, USA.

Rivera-Garza M., Olguin, M.T., Garcia-Sosa I., Alcántara D. \& Rodriguez-Fuentes G. (2000) Silver supported on natural Mexican zeolite as an antibacterial material. Microporous and Mesoporous Materials, 39, 431-444.

Rodriguez-Fuentes G., Ruiz-Salvador A.R., Mir M., Picazo O., Quintana G. \& Delgado M. (1998) Thermal and cation influence on IR vibration of modified natural clinoptilolite. Microporous and Mesoporous Materials, 20, 269-281.

Rodríguez-Iznaga I., Petranovskii $\quad$ V., Castillón-Barraza $\quad$ F. \& Concepción-Rosabal B. (2011) Copper-silver bimetallic system on natural clinoptilolite: thermal reduction of $\mathrm{Cu}^{2+}$ and $\mathrm{Ag}^{+}$exchanged. Journal of Nanoscience and Nanotechnology, 11, 5580-5586.

Rodríguez-Mendez B.G., Lopez-Callejas R., Olguín M.T., Valencia-Alvarado R., Mercado-Cabrera A., Pena-Eguiluz R. \& Munoz-Castro A.E. (2017) Growth of Ag particles from Ag-zeolite by pulsed discharges in water and their antibacterial activity. Microporous and Mesoporous Materials, 244, 235-243.

Şahin Ö., Kaya M. \& Saka C. (2015) Plasma-surface modification on bentonite clay to improve the performance of adsorption of methylene blue. Applied Clay Science, 116-117, 46-53.

Schwanke A.J., Balzer R. \& Pergher S. (2017) Microporous and mesoporous materials from natural and inexpensive sources. Pp. 1-22 in: Handbook of Ecomaterials (L. Martínez, O. Kharissova \& B. Kharisov, editor). Springer, Cham, Switzerland.

Shameli K., Ahmad M.B., Yunus W.M.Z.W., Rustaiyan A., Ibrahim N.A., Zargar M. \& Abdollahi Y. (2010) Green synthesis of silver/montmorillonite/chitosan bionanocomposites using the UV irradiation method and evaluation of antibacterial activity. International Journal of Nanomedicine, 5, 875-887.

Skiba M. \& Vorobyova V. (2018) Green synthesis of silver nanoparticles using grape pomace extract prepared by plasma-chemical assisted extraction method. Molecular Crystals and Liquid Crystals, 674, 142-151.

Suligoj A., Pavlovic P., Arcon I., Rajic N. \& Tusar N.N. (2020) $\mathrm{SnO}_{2}$-containing clinoptilolite as a composite photocatalyst for dyes removal from waste water under solar light. Catalysts, 10, 253.

Taaca K.L.M. \& Vasquez M.R. Jr (2017) Fabrication of Ag-exchanged zeolite/ chitosan composites and effect of plasma treatment. Microporous and Mesoporous Materials, 241, 383-391.

Taaca K.L.M., Nakajima, H., Thumanu K., Janphuang P., Chanlek N. \& Vasquez M.R. Jr (2020) Spectroscopic studies of plasma-modified silverexchanged zeolite and chitosan composites. Materials Chemistry and Physics, 250, 122980.

Tanışlı M., Mertadam S., Poyraz N., Şahin N. \& Demir S. (2016) Inactivation of microorganisms with neon plasma jet at atmospheric pressure. Journal of Pure and Applied Microbiology, 10, 1897-1904.

Tanışlı M., Taşal E., Şahin N. \& Arslan Ç. (2017) 6-(2-Fluorobenzoyl)3-(2-(4-(4-fluorophenyl)piperazin-1-yl)-2-oxoethyl)benzo[d]thiazol-2(3H)-one drug molecule structure and its interaction with atmospheric pressure plasma jet. Journal of Molecular Liquids, 240, 733-751.

Tanışlı M., Taşal E., Şahin N. \& Dikmen G. (2018) An investigation onto the molecular structure of 5-chloro-3-(2-(4-ethylpiperazine-1-il)-2-oxoethyl) benzo[d]thiazole-2 $(3 \mathrm{H})$-on drug molecule before and after atmospheric pressure plasma treatment. Journal of Molecular Structure, 1159, 135-146.

Top A. \& Ulku S. (2004) Silver, zinc, and copper exchange in a Na-clinoptilolite and resulting effect on antibacterial activity. Applied Clay Science, 27, 13-19.

Tosheva L., Belkhair S., Gackowski M., Malic S., Al-Shanti N. \& Verran J. (2017) Rapid screening of the antimicrobial efficacy of Ag-zeolites. Colloid Surfaces B, 157, 254-260.

Tsitsishvili G.V. \& Andronikashvili T.G., editors (1992) Natural Zeolites. Ellis Horwood, Hemel Hempstead, UK, 297 pp.

Unaldı T., Mızrak I. \& Kadir S. (2013) Physicochemical characterisation of natural K-clinoptilolite and heavy-metal forms from Gördes (Manisa, western Turkey). Journal of Molecular Structure, 1054-1055, 349-358.

Velasco-Maldonado P.S., Harnandez-Montoya V., Montes-Moran M.A., Rangel Vasquez N.A. \& Perez-Cruz M.A. (2018) Surface modification of a natural zeolite with cold oxygen plasma: characterization and application in water treatment. Applied Surface Science, 434, 1193-1199.

Wahono S.K., Suwanto A., Prasetyo D.J., Hernawan \& Jatmiko T.H. (2019) Plasma activation on natural mordenite-clinoptilolite zeolite for vapor adsorption enhancement. Applied Surface Science, 483, 940-946.

Wdowin M., Wiatros-Motyka M.M, Panek R., Stevens L.A., Franus W. \& Snape C.E. (2014) Experimental study of mercury removal from exhaust gases, Fuel, 128, 451-457. 
Yavuz O. \& Saka C. (2013) Surface modification with cold plasma application on kaolin and its effects on the adsorption of methylene blue. Applied Clay Science, 85, 96-102.

Youssefa H.F., El-Naggarb M.E., Foudac F.K. \& Youssef A.M. (2019) Antimicrobial packaging film based on biodegradable CMC/PVA-zeolite doped with noble metal cations. Food Packaging and Shelf Life, 22, 100378.
Zaarour M., El Roz M., Dong B., Retoux R. \& Aad R. (2014) Photochemical preparation of silver nanoparticles supported on zeolite crystals. Langmuir, 30, 6250-6256.

Zhao D., Zhou J. \& Liu N. (2007) Surface characteristics and photoactivity of silver-modified palygorskite clays coated with nano sized titanium dioxide particles. Material Characterization, 58, 249-255. 